\title{
ARTIGO
}

$\mathrm{DOI}$

\section{TRANSFORMAÇÕES DOS PARADIGMAS DA ESCOLA TECNICISTA E REFLEXÕES SOBRE A PEDAGOGIA EMPREENDEDORA}

\author{
TRANSFORMATIONS OF THE PARADIGMS OF THE TECHNICIAN SCHOOL AND \\ REFLECTIONS ON ENTREPRENEURSHIP PEDAGOGY
}

\author{
TRANSFORMACIONES DE LOS PARADIGMAS DE LA ESCUELA TECNICISTA Y \\ REFLEXIONES SOBRE LA PEDAGOGÍA EMPRENDEDORA
}

\author{
Antônio José Müller \\ Universidade Regional de Blumenau - Brasil \\ Claudeney Licínio Oliveira \\ Universidade Regional de Blumenau - Brasil \\ Marcos Antonio Fari Junior \\ Universidade Regional de Blumenau - Brasil
}

\section{Resumo}

Este artigo trata de uma pesquisa bibliográfica de cunho exploratório que visa promover reflexões sobre as transformações ocorridas nas propostas pedagógicas da escola tecnicista no Brasil. Além disso, visa problematizar a constituição e implantação da proposta pedagógica empreendedora na escola técnica profissionalizante contemporânea. Através da análise da obra Pedagogia empreendedora de Fernando Dolabela, em conjunto com os conceitos de Saviani, Luckesi e Libâneo sobre as tendências pedagógicas no Brasil, discutiremos sobre a Tendência Pedagógica Liberal Tecnicista e suas transformações metodológicas históricas até chegar aos novos métodos utilizados por uma pedagogia empreendedora. Contextualizamos, assim, conceitos, suas práticas e evoluções, tornando-se mais uma possibilidade para os avanços da qualidade na educação brasileira. Tudo isso no momento em que o governo federal promulga a lei de reforma do Ensino Médio e discute a Base Nacional Comum Curricular. Além disso, a pedagogia empreendedora visa também contribuir para a formação de sujeitos proativos e empreendedores, centralizando suas atenções ao sujeito, dando-lhe vez e voz, e primando por uma formação que atende às novas exigências do mercado de trabalho e às evoluções tecnológicas, econômicas, culturais e sociais.

Palavras-chave: Educação. Escola técnica. Empreendedorismo

\section{Abstract}

This paper deals through an exploratory bibliographical research that aims to promote reflections on the transformations that occurred in the pedagogical proposals of the technical school in Brazil. In addition, it aims to problematize the structure and implementation of the entrepreneurial pedagogical proposal in the 
contemporary technical vocational school. Through the analysis of Entrepreneurial Pedagogy from Fernando Dolabela, together with the concepts of Saviani, Luckesi and Libaneo on pedagogical tendencies in Brazil, we will discuss about the Liberal Technician Pedagogical Tendency and its historical methodological transformations until reaching the new methods used by an entrepreneurship pedagogy. We contextualize concepts, practices and evolutions, becoming one more possibility for the advances of quality in Brazilian education. All this right now when the federal government promulgates the law of reform of High School and discusses the National Common Curricular Base. In addition, entrepreneurial pedagogy also aims to contribute to the development of proactive and entrepreneurial pupils and centralizing their attention to the pupils, giving him time and voice, and giving priority to a training that meets the new demands of the labor market and technological economic, cultural and social developments.

Keywords: Education. Technical school. Entrepreneurship

\section{Resumen}

Este trabajo es una investigación bibliográfica de carácter exploratória que tiene como objetivo estimular reflexiones sobre las transformaciones acontecidas en las propuestas pedagógicas de la escuela tecnicista en el Brasil. El trabajo tiene tambien como objetivo problematizar las constitución y implantación de la propuesta pedagógica empreendedora en la escuela técnica profesionalizante contemporanea. Llevando en cuenta la obra de "Pedagogia Empreendedora" de Fernando Dolabela en conjunto con los conceptos de Saviani, Luckesi e Libaneo sobre las tendencias pedagógicas en el Brasil, discutiremos la tendencia pedagógica liberal-tecnicista y sus transformaciones metodológicas históricas hasta llegara los nuevos métodos utilizados por una pedagogía empreendedora. Colocando en su contextos eses conceptos, prácticas y evoluciones, transformandose en más una posibilidad de mejorar la cualidad en la educación brasileña. El gobierno brasileño actual estableción una Lei de Reforma de la Enseñanza Media y discute la Base Nacional Comun Curricular. Igualmente, la pedagogía empreendedora tiene como objetivo contribuir en la formación de los sujetos proactivos y empreendedores, centralizando sus atenciones en el sujeto, y pretende darle voz y priorizando una formación que atiende a las nuevas exigencias del mercado de trabajo y las evoluciones tecnológicas, económicas, culturales y sociales.

Palavras clave: Educación. Escuela técnica. Emprendedorismo

\section{Introdução}

O processo de ensino-aprendizagem passou por evolutivas mudanças ao longo da história. A busca pelo conhecimento e a motivação para a compreensão dos fatos e fenômenos ocorridos na sociedade e na natureza despertaram inquietações a filósofos, sociólogos e especialistas em 
educação. Isso objetivou discutir e propor novas possibilidades no ato de ensinar e aprender e na construção do conhecimento promovido pelas instituições de ensino, contribuindo para a evolução da ciência, da tecnologia, da formação intelectual dos sujeitos e para as transformações sociais.

Martins (1994) destaca grandes filósofos como Rousseau, Voltaire, Locke, Montesquieu, Kant, Smith, Durkheim e Marx, entre outros, responsáveis pela evolução do conhecimento filosófico e científico através de suas obras. Tanto que inspiraram diversos estudiosos da área da educação e da ciência, que consequentemente passaram a nortear a educação desde a institucionalização da escola aos métodos utilizados por ela ao longo do tempo.

Ademais, os professores Libâneo (1990/1995), Saviani (1981/2008) e Luckesi (2003) fazem uma reflexão sobre as tendências pedagógicas no Brasil, as quais estão enquadradas em duas grandes linhas de pensamento pedagógico: Tendências Pedagógicas Liberais e Tendências Pedagógicas Progressistas. Em relação à primeira, Filho (201 1, p. 12) destaca que

[...] a pedagogia liberal tem por função preparar o indivíduo para papéis sociais, de acordo com aptidões e interesses de cada um. São as pessoas que devem se adaptar às normas e às condições existentes na sociedade, onde as relações de classes sociais não são consideradas.

No entanto, as tendências pedagógicas progressistas vão numa direção oposta, vendo a educação como uma força da luta de classes, visando transformar a ordem social e econômica, e pregando um engajamento político dos atores envolvidos no processo educativo. Segundo Teixeira (2003, p. 93),

As pedagogias progressistas encontram duas concepções básicas: a Pedagogia Libertadora, ligada aos vários setores dos movimentos populares e de educação de adultos, com grande contribuição de Paulo Freire e seus colaboradores, e a Pedagogia Crítico-Social dos Conteúdos, que busca uma síntese superadora de traços significativos da Pedagogia 
Tradicional e da Escola Nova.

Dessa forma, pode-se constatar que as duas tendências pedagógicas estão enraizadas no contexto educacional da atualidade. A proposta pedagógica adotada no processo educativo determina e mostra as ideologias e os objetivos da escola no contexto da formação docente e discente, o que de certa forma influi no comportamento e na atuação da sociedade. As concepções pedagógicas norteiam quais os objetivos e as metas a serem alcançadas, e quais as práticas a serem desenvolvidas, de acordo com as demandas da escola, do mercado e da sociedade.

Outro aspecto relevante é que a educação contemporânea atua em um processo educativo estabelecendo uma contextualização social e destacando a prática pedagógica através das relações dialógicas, o que propicia a reflexão sobre o ato de ensinar e aprender e o fortalecimento dos conhecimentos constituídos por estudantes e professores. Segundo Libâneo (1995, p. 19), a educação promovida pela escola tem objetivos de "assimilação de conhecimentos e experiências humanas acumuladas no decorrer da história", considerando a formação e as relações dos sujeitos sociais.

Levando em consideração que a prática escolar sempre esteve sujeita a condicionantes de ordem sociopolítica e de capital/poder, é relevante a discussão sobre os fluxos, evoluções e transformações da educação e da sociedade. E o surgimento do termo 'empreendedorismo' foi um marco relevante nas discussões sobre as tendências pedagógicas na educação. Depois de um passado marcado pela educação tecnicista, voltada ao fornecimento de mão de obra qualificada para o mercado de trabalho, ser empreendedor é uma condição socioeconômica muito mais acessível às pessoas do que em outros tempos.

Portanto, o objetivo deste artigo é problematizar a educação empreendedora no contexto atual em relação à pedagogia tecnicista tradicional. A partir de uma análise qualitativa, o texto trata de uma pesquisa exploratória, bibliográfica e documental, e seus objetivos específicos são 
abordar o surgimento da educação tecnicista, as mudanças dessas concepções até o contexto atual, e a reflexão da educação empreendedora como uma possibilidade de ressignificar esse modelo de formação.

Por isso, fundamentamos esta pesquisa sobre a escola tecnicista através das reflexões de Saviani, Libâneo e Lukesi, abordando sua concepção, seus pontos positivos e negativos e como ela se constitui no Brasil, e principalmente a proposta de Dolabela com a pedagogia empreendedora como uma nova possibilidade no processo de ensinar e aprender, propondo também ser incorporada aos demais segmentos escolares.

\section{O conhecimento, o capitalismo e a constituição da educação tecnicista}

Para discutir as práticas pedagógicas contemporâneas das escolas técnicas e dos programas que realizam cursos profissionalizantes no Brasil, torna-se necessário fazer um regaste dos processos que fundamentam ideologias e discussões sobre o conhecimento e suas contribuições para a reorganização social, econômica e cultural mundial, iniciada no continente europeu a partir do século XVII pelos ideais iluministas que posteriormente se espalharam para os demais continentes, tornando o regime capitalista como modelo para as demais sociedades.

Martins (1994) chama atenção para o desencadeamento da Revolução Francesa no século XVIII, quando os filósofos buscavam transformar as formas de conhecimento, ainda dominado pelo dogmatismo e autoridade da Igreja, que privilegiava a burguesia imperialista/feudal. Os iluministas, formados por pensadores e filósofos burgueses, posicionavam-se contra o regime feudal e sua classe dominante.

Ainda segundo Martins (1994), os conflitos ocorridos na França se intensificaram entre a burguesia intelectual, que objetivava aderir aos regimes capitalistas, e a monarquia absolutista, que queria manter seu 
regime e os privilégios para a classe dominante feudal. Entretanto, foi a partir de 1789 que a burguesia francesa fortalecida toma o poder e constitui um Estado, visando implantar a autonomia em relação aos domínios da Igreja e objetivando incentivar e proteger a empresa capitalista. A priori, contaram com o apoio dos trabalhadores pobres.

Assim, a sociedade francesa passou por uma transformação histórica: o fim dos privilégios feudais, aristocráticos e religiosos, isso devido ao ataque das massas nas ruas e de grupos políticos radicais e de camponeses na região rural do país, os quais, logo após conquista, foram oprimidos pela nova classe dominante.

É nesse período de grandes transformações, revoluções e discursos ideológicos e filosóficos que surgem as reformas e contrarreformas sobre as quais se instaura a pedagogia, como forma de organizar o ensino na classe, o que iria acolher um grande número de alunos pelas escolas urbanas. A Europa e grande parte do mundo, então, fundamentadas pelo regime capitalista, buscariam na educação as ferramentas necessárias para a formação da nova ordem social, preparando os sujeitos para atender as demandas do mercado de trabalho e ao sistema capitalista.

As discussões sobre o conhecimento humano têm como divisor de águas dois grandes momentos históricos que mudaram radicalmente as discussões sobre o conhecimento, a organização social, cultural, econômica e política do mundo. São eles: a Revolução Francesa e a Revolução Industrial. Elas promoveram a queda do regime imperialista/feudal, ascendendo o regime capitalista, o que colocou em evidência uma nova forma de pensar, discutir e promover o conhecimento humano e o processo de ensino e aprendizagem nas escolas e academias.

As transformações econômicas, políticas e culturais que se aceleram a partir dessa época colocarão problemas inéditos para os homens que experimentavam as mudanças que ocorriam no ocidente europeu. A dupla revolução que este século testemunha - a industrial e a francesa - constituía os dois lados de um mesmo processo, qual seja, a instalação definitiva da sociedade capitalista. (MARTINS, 1994, p. 5). 
Sobre as discussões que avançaram a partir do século XVII, Martins (1994), ao refletir sobre as ideias de Bacon, destaca que a libertação do conhecimento sob o domínio da Igreja significava a saída do teologismo para o ramo da razão humana, da ciência e da tecnologia, conduzindo a uma nova atitude os intelectuais do conhecimento frente aos fenômenos da natureza e da cultura.

A fundamentação e o desencadeamento do capitalismo, que tomou conta da Europa e se espalhou pelo restante do mundo, promoveram também a invenção da Escola como instituição para obedecer e atender as demandas da nova ordem social do "capital". O conhecimento e os processos de ensino e aprendizagem tomam conta das atenções dos pensadores e da burguesia que pretendiam formar sujeitos para atender as demandas e a mão de obra das fábricas.

Ao discutir a educação e o conhecimento, Biesta (2013) se reporta aos ideais dos iluministas ao considerar que "a educação havia se tornado em verdade particular sobre a natureza e o destino do homem". Outro fator relevante que ele menciona é a chamada "Santíssima Trindade" do projeto iluminista, que compreende: a racionalidade, a autonomia e a educação, que se tornaram bases fundamentais inspiradoras para abordagens críticas da educação para Hegel e Marx; e mais tarde, Paulo Freire, compreendendo a educação como um processo que possibilita o desenvolvimento racional e a autonomia das pessoas.

Por um lado, segundo Martins (1994), a Revolução Industrial representou um triunfo da indústria capitalista para a burguesia, convertendo grandes massas humanas em meros trabalhadores despossuídos de renda e poder, ou seja, em assalariados que lutavam para sobreviver.

A formação de uma sociedade que se industrializa e urbanizava em ritmo crescente implicava a reordenação da sociedade rural, a destruição da servidão, o desmantelo da família patriarcal etc. A transformação da atividade artesanal em manufatureira e, por último, em atividade fabril, 
desencadeou uma maciça emigração do campo para a cidade, assim como engajou mulheres e crianças em jornadas de trabalho de pelo menos doze horas, sem férias e feriados, ganhando um salário de subsistência. (MARTINS, 1994, p. 6).

O autor ressalta também que outro fator determinante da Revolução Industrial foi o surgimento do proletariado discriminado e criminalizado pela burguesia, o que deu origem às revoltas dos trabalhadores explorados por seus patrões dominantes. Isso espalhou diversas manifestações da classe trabalhadora e também a criação de associações livres e sindicatos, tornando uma classe operária consciente de seus interesses e mudando seus ideais para o sistema socialista.

Ao contrário do positivismo, que procurou elaborar uma ciência social supostamente "neutra" e "imparcial", Marx e vários de seus seguidores deixaram clara a íntima relação entre o conhecimento por eles produzido e os interesses da classe revolucionária existente na sociedade capitalista, o proletariado. Observava Marx, a este respeito, que assim como os economistas clássicos eram os porta-vozes dos interesses da burguesia, os socialistas e os comunistas constituíam, por sua vez, os representantes da classe operária. (MARTINS, 1994, p. 31).

Depois, a teoria marxista evidencia o Estado capitalista como um órgão repressor que fortalece e assegura às classes dominantes seu poder de domínio e exploração sobre a classe trabalhadora, e se fundamenta em situações opostas sob condições sociais, culturais e econômicas bem definidas e separadas: patrão e operário, progresso e atraso, riqueza e pobreza, liberdade e escravidão. Destacava ainda a educação como parte da superestrutura e de um meio de dominação no capitalismo, processo que, ao todo, potencializa a alienação do sujeito.

A economia política oculta a alienação na característica do trabalho enquanto não analisa a imediata relação entre o trabalhador (trabalho) e a produção. É evidente, o trabalho produz coisas boas para os ricos, mas produz a escassez para o trabalhador. Produz palácios, mas choupana para o trabalhador. Produz beleza, mas deformidade para o 
trabalhador. Substitui o trabalho por máquinas, mas encaminha uma parte dos trabalhadores para um trabalho cruel e transforma os outros em máquinas. Produz inteligência, mas também produz estupidez e a cretinice para os trabalhadores. (MARX, 2001, p. 113).

Segundo Paulo Freire (1987, p. 27), "O invasor pensa, na melhor das hipóteses, sobre os segundos, jamais com eles; estes são 'pensados' por aqueles. O invasor prescreve; os invadidos são pacientes da prescrição". Quanto à educação, o mesmo autor acreditava que a educação bancária é monológica e conduz à opressão, e os estudantes são considerados objetos. Somente uma pedagogia libertadora poderia levar os oprimidos à liberdade. Dessa feita, Paulo Freire (1987, p. 55) destaca ainda que: "Até o momento em que os oprimidos não tomem consciência das razões de seu estado de opressão 'aceitam' fatalistamente a sua exploração".

Desse modo, a educação com base nos princípios do regime capitalista eclode nas sociedades mundiais. Contudo, foi a partir do século XX que surgiu nos Estados Unidos da América a Pedagogia Tecnicista, com foco na mão de obra especializada para as indústrias crescentes no país. Segundo Saviani (1986, p. 16), "na pedagogia tecnicista [...] é o processo que define o que professores e alunos devem fazer, e assim também, quando e como o farão". A metodologia de ensino utilizada era nos moldes de produção taylorista: o aluno era preparado para exercer sua função/tarefa na fábrica e executar suas tarefas em menor tempo possível na produção. Não havia necessidade de conhecimento do processo final de resultado com padronização e execução de atividades simples e repetitivas; o conhecimento e a responsabilidade pelo sucesso do trabalho e da produção eram atribuições do gerente.

Saviani (1986) faz referências de que o fordismo destacou-se pela organização do trabalho em linhas de montagens. O aluno/funcionário era preparado e se especializava apenas para uma parte do processo produtivo, sendo responsável para uma única função em um determinado espaço fixo na linha de montagem, pois o produto fabricado se deslocava 
por uma esteira (no caso, o automóvel). Esse modelo foi adotado pelo Brasil através de acordos e convênios com os Estados Unidos para atender as expectativas capitalistas brasileiras.

Enfim, após todos os eventos históricos descritos acerca das transformações socioeconômicas que influenciaram os modelos instituídos no processo educacional, apresentamos, a seguir, a interferência desses eventos na organização social, política, econômica e cultural, e também na educação brasileira, com base nos documentos oficiais como a Constituição Federal Brasileira e a Lei de Diretrizes e Bases, e em como a escola tecnicista foi implantada no Brasil.

\section{Os desdobramentos das concepções teóricas da escola tecnicista brasileira}

No Brasil a educação iniciou os primeiros passos junto com o processo de colonização pelos europeus, nos moldes de regimes monárquico e religioso. $\bigcirc$ processo de ensino e aprendizagem foi marcado pela catequização dos indígenas pelos jesuítas aos domínios da coroa e da burguesia de origem portuguesa. No ano de 1822 havia propostas para a institucionalização da educação na Assembleia Constituinte inspiradas nos ideais da Revolução Francesa, o que não foi adiante, sofrendo cortes por Dom Pedro I, que inibiu qualquer tentativa de estruturar uma política nacional de educação.

Em 1824, foi outorgada a primeira Constituição Brasileira que garantia a instrução primária e gratuita para todos os cidadãos. Porém, a partir do ano de 1927, foi aprovada a primeira lei sobre o ensino primário no Brasil. Em 1946, foi criada a Constituição que compreende a Nova República (19461963), colocando o ensino primário como obrigatoriedade e dando competência à União para legislar sobre as diretrizes e bases da educação nacional.

A primeira LDB $n^{\circ} 4024 / 61$ foi publicada em 20 de dezembro de 1961, mas já havia sido prevista na Constituição Brasileira de 1934 que, em seus artigos, determinava: autonomia aos órgãos estaduais; regulamentação dos 
Conselhos Estadual e Federal de Educação; definiam o empenho de recursos do Estado e da União; obrigatoriedade de matrícula do ensino primário; formação de professores; ano letivo de 180 dias; ensino religioso facultativo; permissão do ensino experimental etc.

Devido ao regime militar do então presidente Emílio Garrastazu Médici, ocorreram várias intervenções no processo educacional, o que deu origem à criação da segunda LDB n 5692/71, publicada no dia 11 de agosto de 1971, com 88 artigos. Além dos previstos na lei anterior, destacam-se: prevê um núcleo comum para os currículos de $1^{\circ}$ e $2^{\circ}$ graus e uma parte diversificada em função das peculiaridades; inclusão da Educação Moral e Cívica, Educação Física, Educação Artística e programas de saúde como matérias obrigatórias do currículo; os municípios devem gastar $20 \%$ de seu orçamento com educação; não prevê dotação orçamentária para a União ou os estados; progressiva substituição do ensino de $2^{\circ}$ grau gratuito por um sistema de bolsas com restituição; e pagamento por habilitação.

Após a queda do regime militar, a chegada da democracia foi a promulgação da Constituição Brasileira de 1988, o que deu condições para a publicação das novas propostas para a educação brasileira, baseada no princípio do direito universal à educação para todos. A LDB n 9394/96 foi sancionada pelo presidente Fernando Henrique Cardoso em 20 de dezembro de 1996, e teve como relator Darcy Ribeiro.

Essa nova lei trouxe várias mudanças em relação às leis anteriores (LDB $n^{\circ}$ 4024/61 e n 5692/71), em destaque a inclusão da educação infantil para atendimentos em creches e pré-escolas como primeira etapa da educação básica; carga horária de 800 horas com o mínimo de duzentos dias letivos; gestão democrática; prevê a criação do Plano Nacional de Educação etc. Possui assim 92 artigos e várias ementas que norteiam a educação brasileira atual e já passou por reformas.

Os professores Libâneo (1990/1995), Saviani (1981/2008) e Luckesi (2003) destacam que as principais tendências pedagógicas usadas na educação brasileira se dividem em duas grandes linhas de pensamento pedagógico: 
TENDÊNCIAS PEDAGÓGICAS LIBERAIS, compostas pela as tendências: Tradicional, Renovadora Progressista, Escola Nova e Tecnicista, e TENDÊNCIAS PROGRESSISTAS, compostas pelas tendências: Libertadora, Libertária e Crítico-Social dos Conteúdos ou Histórico-Crítica.

Por mais que seja de grande importância discutir sobre todas as tendências pedagógicas para compreender a evolução da educação brasileira, vamos nos deter na Tendência Pedagógica Liberal Tecnicista.

Assim, a Educação Tecnicista, segundo Luckesi (2003), com bases inspiradas nos modelos de ensino dos Estados Unidos da América, foi introduzida no Brasil na década de 1960 (durante o regime militar), com a implantação de programas de desenvolvimento econômico e social, denominados ALIANÇA PARA O PROGRESSO e MEC-SAID, em convênio entre Estados Unidos e Brasil, através das promulgações das Leis 5540/68 e 5692/71, reformulando o Ensino Superior e instituindo o Ensino de $1^{\circ}$ e $2^{\circ}$ Graus.

Para Luckesi (2003), à escola foi imputado o papel de divulgar o modelo de ensino e produção capitalista, pois a pedagogia tecnicista era constituída com uma metodologia específica que propunha à escola a função de preparar e treinar o aluno para exercer papéis sociais, funcionais, assimilação das normas e valores através do desenvolvimento da sua própria cultura, estimulando suas aptidões e habilidades e produzindo sujeitos capazes e eficientes para o desempenho de funções no mercado de trabalho.

Assim, de um lado surgiam tentativas de desenvolver uma espécie de "Escola Nova Popular", cujos exemplos mais significativos são as pedagogias de Freinet e de Paulo Freire; de outro lado, radicalizava-se a preocupação com os métodos pedagógicos presentes no escolanovismo que acaba por desembocar na eficiência instrumental. Articula-se aqui uma nova teoria educacional: a pedagogia tecnicista. (SAVIANI, 2008, p. 10).

Saviani (2008) considerava que as teorias da educação se classificariam em dois grupos, levando em consideração as questões da 
marginalidade e sua explicação através de um paralelo entre a educação e a sociedade. O primeiro seria pelas "Teorias não críticas" compostas pela Pedagogia Tradicional, Pedagogia Nova e Pedagogia Tecnicista, cujas concepções vislumbram uma educação como um instrumento de equalização social, como uma superação da marginalidade, sendo considera como um desvio, e cabendo à educação a função de corrigi-lo. O segundo grupo seria composto pelo que Saviani denominava "Teorias Crítico-Reprodutivas", abrangendo a Teoria do sistema de ensino como Violência Simbólica, a Teoria da Escola Dualista e a Teoria da Escola como Aparelho do Estado. Em tal contexto, sendo a educação vista como um instrumento de discriminação social e o fator de marginalização visto como um problema social, cabe à educação, que dispõe de autonomia em relação à sociedade, fazer intervenções eficazes transformando e promovendo a equalização social.

Ao discutir as Tendências Pedagógicas, Libâneo (1990) ressalta que a pedagogia liberal fundamenta a ideia de que são atribuições da escola preparar os indivíduos para desempenhar papeis de cunho social, levando em conta suas aptidões e habilidades individuais. Partindo desse pressuposto, os indivíduos necessitam se adaptar às regras e aos valores constituídos na sociedade de classes.

Embora a escola possa difundir os princípios de igualdade e oportunidades, esta não leva em conta a desigualdade de condições. Sobre a escola liberal tecnicista, o autor ressalta que esta atua no aperfeiçoamento da ordem social vigente, de forma articulada com o sistema produtivo ao benefício do sistema capitalista, a mudança do comportamento, denominado como tecnologia comportamental, cujo interesse é produzir indivíduos "competentes" para o mercado de trabalho, deixando de lado as preocupações com as mudanças sociais.

Segundo Saviani (2008, p. 24), "Enquanto as teorias não críticas pretendem ingenuamente resolver o problema da marginalidade por meio da escola sem jamais conseguir êxito, as teorias crítico-reprodutivistas 
explicam a razão do suposto fracasso". Ele ressalta também que foi por exaustão da escola nova, na primeira metade do século $X X$, que a educação passou por momentos de desilusão, visto que a nova pedagogia e a tradicional não atendiam às aspirações do momento pelo qual o país passava. Então a tendência tecnicista iria pôr em prática uma organização racional que diminuiria as interferências, e não pôr em risco sua eficiência, sendo necessário mecanizar o processo, objetivando propagar propostas pedagógicas "como o enfoque sistêmico, microensino, tele-ensino, a instrução programada, as maquinas de ensinar etc.".

A pedagogia liberal sustenta a ideia de que a escola tem por função preparar o indivíduo para o desempenho de papéis sociais, de acordo com as aptidões individuais. Para isso, os indivíduos precisam aprender a adaptar-se aos vários valores e às normas vigentes na sociedade de classes, através de desenvolvimento da cultura individual. A ênfase no aspecto cultural esconde a realidade das diferenças de classes, pois, embora difundida a ideia de igualdade de oportunidades, não leva em conta a desigualdade de condições. (LIBÂNEO, 1990, p. 22).

As práticas pedagógicas a serem implementadas teriam que ser previamente planejadas, ajustando-se às diferentes disciplinas dentro do contexto teórico da tendência tecnicista, colocando professor e aluno em uma condição secundária: de um lado o professor, que sofre as intervenções que corrigem suas deficiências através de especialistas neutros, objetivo e imparciais; do outro, o aluno que é receptor passivo de conteúdos específicos, acumulando informações simples ou complexas previamente definidas sobre o que professores e alunos devem fazer, e quando e como irão fazer.

Compreende-se, então, que para a pedagogia tecnicista a marginalidade não será identificada com a ignorância nem será detectada a partir do sentimento de rejeição. Marginalizado será o incompetente (no sentido técnico da palavra), isto é, o ineficiente e improdutivo. A educação estará contribuindo para superar o problema da marginalidade na medida em que formar indivíduos eficientes, portanto, capazes de darem sua parcela de contribuição 
para o aumento da produtividade da sociedade. (SAVIANI, 1981 , p. 11).

A tendência tecnicista tem por princípios produzir sujeitos para o mercado de trabalho, transmitindo informações precisas, objetivas e rápidas. Os conteúdos abordam princípios científicos, leis, etc., planejados por especialistas específicos e habilitados. Geralmente não há lugar para o aluno atuar, agir ou reagir de forma individual sem atividades que estimulem a criatividade e o senso crítico dos alunos. As aulas são expositivas, com muita teoria e exercícios sistematizados para a memorização.

A prática pedagógica encontra-se voltada para a aplicação sistemática de princípios científicos comportamentais, cujo papel do professor é administrar as condições de transmissão de conteúdos, cabendo ao aluno executar o sistema instrucional previsto. Neste aspecto, o processo de ensino e aprendizagem decorre do comportamento operante, por meio da utilização de princípios e estratégias próprias da psicologia behaviorista. (LUCKESI, 2003).

Segundo Luckesi (2003), a metodologia do modelo de educação tecnicista seria assegurar a transmissão e recepção dos conteúdos e das informações. O professor modela respostas com foco nos objetivos e procedimentos instrucionais programados como a avaliação, cuja aplicação torna-se sistemática, embasados em princípios tecnológicos, comportamentais e científicos. As relações em sala de aula são estruturadas, deixando claros e definidos os papéis de cada um: a função do professor é ministrar os conteúdos da matéria/disciplina como previamente planejados e previstos no programa educacional e manter a ordem. Já ao aluno, sujeito passivo, cabe receber, aprender e fixar as informações. Assim não existem relações de afetividade, o que torna a relação professor/aluno extremamente técnica, pois não existe espaço para debates e posicionamentos abertos de opinião.

Saviani (2008, p. 12) é muito categórico em dizer que "[...] a pedagogia tecnicista acabou por contribuir para aumentar o caos no campo educativo gerando tal nível de descontinuidade, de 
heterogeneidade e de fragmentação, que praticamente inviabiliza o trabalho pedagógico". Segundo o autor, este método fragmentou o ato pedagógico, fazendo o magistério ser submetido basicamente ao preenchimento de formulários, como se fosse um ritual repetitivo a exemplo do funcionamento fabril e, quanto aos resultados serem negativos, "ignorou que a articulação entre a escola e processo produtivo se dá de modo indireto e através de complexas mediações".

É nesse período que a escola tecnicista cruza com as propostas das escolas tradicionais e com a influência de metodologias da escola nova, que chamava atenção, tornando-se atrativa para os educadores. Dessa forma, agravou-se a situação do problema da marginalidade, uma vez que o aumento de vagas para as escolas tecnicistas não atraíam mais alunos, além de resultados de altos índices de evasão e repetências.

Todos esses fatores dispostos por Saviani foram percebidos, em particular, na América Latina, visto que se desviou das "atividades-fim para atividades-meio", e escassos recursos destinados à educação. Saviani faz um questionamento sobre os reais interesses para a implantação desses programas de ensino, pois havia interesses de vendas de artefatos tecnológicos obsoletos dos países desenvolvidos para os países subdesenvolvidos.

Assim, a expansão do sistema capitalista pelo mundo, os avanços tecnológicos e o processo de globalização causaram grandes mudanças aos modelos econômico, social e político e à formação educacional dos sujeitos para atender as novas exigências do capitalismo moderno. Desta feita, a pedagogia tradicional não seria suficiente para atender tais exigências, necessitando de se reinventar, criar novos conceitos e métodos inovadores, futuristas e proativos. É dessa forma que surge a Pedagogia Empreendedora.

\section{Pedagogia empreendedora: a redenção da escola técnica}

Uma ruptura no modelo tradicional de educação tecnicista apareceu 
com o fenômeno do empreendedorismo no Brasil, conceito surgido já no século XVIII, e a partir de então diversas pesquisas evidenciaram que o empreendedorismo é um dos principais fatores de desenvolvimento econômico (DOLABELA, 1999, p. 40). Assim, o empreendedorismo incorporado na educação tecnicista proporciona aos estudantes que sejam protagonistas da própria história, podendo mudar a realidade em que se encontram, utilizando os seus conhecimentos para tal.

Para Dolabela, a sociedade e nosso sistema educacional contaminam nossos jovens com a "síndrome do empregado", destacado pelo autor também como "síndrome de dependência", que restringe a visão da educação voltada especialmente pela conquista e manutenção do emprego.

Essa concepção de educação pode ser verificada nas diretrizes curriculares nacionais da educação básica. Norteada por recomendações da Organização Internacional do Trabalho (OIT), o documento dessas diretrizes objetiva (BRASIL, 2012, p. 212): "[...] enfatizar a necessidade de se partir da identificação das necessidades do mundo do trabalho e das demandas da sociedade, para se promover o planejamento e o desenvolvimento de atividades de Educação Profissional e Tecnológica".

Essas diretrizes abordam as mudanças dos objetivos da educação profissional técnica em relação ao mundo moderno, de uma maneira muito superficial, incluindo alguns conceitos sobre a necessidade de aproximação dos conteúdos com a prática, orientada pelo conhecimento científico e tecnológico, porém, enfatizando sempre na requalificação do estudante para o trabalho, conforme a seguir.

O futuro do trabalho no mundo dependerá, em grande parte, do desenvolvimento da educação, desde que se consiga garantir sólida educação geral de base para todos e cada um dos seus cidadãos, associada a sólidos programas de Educação Profissional para seus jovens em processo formativo e seus adultos em busca de requalificação para o trabalho (BRASIL, 2013, p. 212). 
Essa requalificação é seguida de um discurso da necessidade de formação continuada, voltada apenas para a melhoria das condições do trabalho. "Nessa nova realidade, é impossível para todos os cidadãos e em especial para os trabalhadores passar algum minuto sem aprender" (BRASIL, 2013, p. 212). Porém, as diretrizes não relacionam esses saberes com outras dimensões além do mundo do trabalho. Esta é a concepção convencional da escola tecnicista.

Dolabela (2003) faz uma reflexão entre a escola que ele denomina convencional e a escola que atua com a pedagogia empreendedora. Para ele, a primeira (convencional) atua numa base de segurança e de aparência de autoridade, com conteúdos que são desenvolvidos e considerados como verdades. Para fundamentar suas ideologias quanto aos desafios e mudanças, o autor recorre, na educação, ao que ele chama de brilhante espírito que, segundo Paulo Freire \& Beto (2000) apud Dolabela (2003, p. 30), "A vida na sua totalidade me ensinou como grande lição que é impossível assumi-la sem risco". Assim, ainda nos ideais de Freire, torna-se necessário compreender e vivenciar na prática que o conhecimento não é transferido, mas construído pela curiosidade e pela motivação.

Como professor devo saber que sem a curiosidade que me move, que me inquieta, que me insere na busca, não aprendo nem ensino. Exercer a minha curiosidade de forma correta é um direito que tenho como gente [...] (FREIRE, 1996, p. 95).

O autor utiliza a obra de Paulo Freire para fundamentar suas ideologias, pois na escola empreendedora os componentes estruturais são fundamentados nas incertezas, vislumbrando a valorização da autoestima, do potencial e das capacidades dos alunos, tornando-os proativos, capazes de solucionar problemas, corrigir erros e superações de fracassos.

O saber empreendedor ultrapassa o domínio de conteúdos científicos, técnicos, instrumentais. Estes pouco servem para quem não sonha, para quem não tem a capacidade de, a partir do sonho, gerar novos conhecimentos que produzam mudanças significativas para 0 avanço da coletividade. A 
"rebeldia" do empreendedor não se manifesta somente pela denúncia do inadequado, do obsoleto, do prejudicial à sociedade, mas sobretudo pela proposta de solução ou melhoria para os problemas que encontra. Por isso, só o sonho (ou a ideia) não é suficiente para configurar uma ação empreendedora: é preciso transformá-lo em algo concreto, visível, sedutor por sua capacidade de trazer benefícios para todos, o que the dá o caráter de sustentabilidade (DOLABELA, 2003, p. 29).

Esse ideal de transformação da pedagogia empreendedora transcende os aspectos operacionais proporcionados pela educação tecnicista tradicional, e se alinha ao que Freire define como 'práxis', "que é a ação dos homens sobre o mundo, para transformá-lo" (2014, p. 52). Assim a pedagogia empreendedora visa um engajamento do sujeito com relação ao contexto em que se insere, problematizando sua relação com o mundo. Essa problematização é importante, pois:

Quanto mais se problematizam os educandos, como seres no mundo e com o mundo, tanto mais se sentirão desafiados. Tão mais desafiados, quanto mais obrigados a responder ao desafio. Desafiados, compreendem o desafio na própria ação de captá-lo. Mas, precisamente porque captam o desafio como um problema em suas conexões com os outros, num plano de totalidade e não como algo petrificado, a compreensão resultante tende-se a tornar crescentemente crítica [...] através dela, que provoca novas compreensões de novos desafios, que vão surgindo no processo da resposta, se vão reconhecendo, mais e mais, como compromisso. Assim é que se dá o reconhecimento que engaja. (FREIRE, 2014, p. 98).

Segundo Dolabela (2003, p. 24), existe um mito de que o empreendedor é nato, individual, mas em sua concepção: "O espírito empreendedor é um potencial de qualquer ser humano e necessita de algumas condições indispensáveis para se materializar e produzir efeitos". Desta feita, ele destaca que as condições estão no ambiente macro, na democracia, na corporação e na estrutura de poder (rede). O autor destaca ainda a importância de investimentos para a formação e capacitação do capital humano para que possa haver a possibilidade de todos tirarem proveito do crescimento e desenvolvimento econômico. 
Quanto ao currículo, Dolabela (2003, p. 24), questiona que o sistema educacional brasileiro deverá rever sua estrutura curricular "para além de conhecimentos técnicos e científicos, cada vez mais indispensáveis e, ao mesmo tempo, menos suficientes para a inserção livre do homem no mundo do trabalho". A escola tecnicista tradicional tem como eixo norteador o saber técnico-científico que geralmente não leva em conta a base de experiência do indivíduo. E, tendo em vista a velocidade com que as coisas mudam, o estudo das oportunidades também deve fazer parte do currículo escolar, dado o fato de que a capacidade de "identificar oportunidades e a de gerar conhecimentos constituem um novo padrão de pré-requisitos para a inserção no mundo do trabalho" (DOLABELA, 2003, p. 23).

Essa nova concepção de incluir o sujeito na proposta do currículo é uma característica da Pedagogia Empreendedora, compreendida como uma plataforma que é constituída por

[...] "saberes" acumulados na história de vida do indivíduo e que são os chamados "quatro pilares da educação" aprender a saber, aprender a fazer, aprender a conviver e aprender a ser -, constantes do Relatório para a Unesco da Comissão Internacional sobre a Educação para o Século XXI (DOLABELA, 2003. p. 26).

Dolabela (2003, p. 55) ainda propõe a proposta pedagógica empreendedora como:

[...] uma estratégia didática para o desenvolvimento da capacidade empreendedora da educação infantil até o nível médio, que utiliza a Teoria Empreendedora dos sonhos, não se propondo a ser uma metodologia educacional de uso amplo. Restrita ao campo do empreendedorismo, conviverá com as diretrizes fundamentais do ensino básico adotadas no ambiente de sua aplicação: a escola.

Quanto à linguagem da Pedagogia Empreendedora, esta se embasa na construção de conhecimento pelo próprio aluno, com linguagem simples, clara, de fácil entendimento partindo da sua realidade, com ferramentas que contribuem para qualificar habilidades, sua comunicação e seu 
conhecimento. Filion (1991) apud Dolabela (2003) destaca os elementos de suporte adaptados pela Pedagogia Empreendedora que os organizou segundo a natureza interna e externa do conhecimento. São eles:

1. Desenvolvimento de condições para o entendimento e o desenvolvimento do próprio ser lautoestima, autoconhecimento, autonomia, protagonismo, sistema de valores, diferenciação, criatividade, energia, capacidade de análise, capacidade de lidar com o risco, conhecimento da natureza do sonho).

2. Desenvolvimento de habilidades e competências para entender fenômenos exógenos, ambientais, e lidar com eles: conhecimento do ambiente em que o sonho se insere; capacidade de tecer uma rede de relações para dar suporte à realização do sonho; identificação de oportunidades.

O autor destaca ainda que essa pedagogia não necessitará de especialistas, apenas da preparação/formação do professor, que já atua na rede formal implantada, e que a base do aprendizado está muito próxima àquela idealizada por Vigotsky (Zona de Desenvolvimento Proximal - ZDP), em que a criança aprende com a convivência e a interatividade com outras pessoas, estimulando suas habilidades, capacidades, imaginação criadora e assimilação de informações.

Então, o papel do professor na Pedagogia Empreendedora não será diminuído, segundo Dolabela (2003, p. 103), visto que a base do aprendizado da teoria empreendedora é o autoconhecimento, mas a função do educador é de extrema relevância, pois "cabe a ele ampliar das referências e fontes de aprendizado e redefinir o próprio conceito de saber".

Por fim, Dolabela (2003) faz referências e descreve os desafios da Pedagogia Empreendedora que as tornam relevantes para atenderem as novas demandas da educação no país. Desses desafios, destacamos os mais relevantes: explicitar objetivamente uma intencionalidade; adotar postura ética; estar afinada com a agenda nacional de desenvolvimento; apoiar-se nas raízes culturais da comunidade, do município, da região, do país; considerar a comunidade como verdadeiro espaço de aprendizado; 
possibilitar que a metodologia seja "recriada"; evitar a rigidez; atingir (principalmente) as populações carentes; não pretender "ajustar" pessoas a um modelo externo; eliminar a distância entre sonho, emoção e trabalho; apoiar-se em fundamentos de cooperação, rede e democracia.

Vale ressaltar a reflexão de Dolabela (2003) quanto à sua ideologia acerca da Pedagogia Empreendedora como promotora de conhecimento e desenvolvimento humano e social:

Se tudo o que foi dito fizer sentido, como feito para os países que buscam o desenvolvimento, independentemente de sistema econômico, cor, política ou preferência ideológica, a educação empreendedora deve ser propagada com intensidade e máxima urgência. (DOLABELA, 2003, p. 136)

Essa reflexão sobre a pedagogia empreendedora se faz necessária pelo advento de grandes mudanças na educação brasileira, que afetam principalmente o ensino médio. As mudanças e as exigências de formas diferenciadas para o ensino no Brasil estão em discussão, ainda de forma tímida, com escolas, profissionais da educação e a sociedade, através da Base Nacional Comum Curricular. E mesmo sem um grande debate nacional sobre o tema, de forma rápida e surpreendente, a presidência da república, através do Ministério da Educação (MEC) sancionou recentemente a Lei 13.415/ 2017, que trata da reforma do Ensino Médio.

Essa lei foi criada subestimando-se o atual modelo de formação, definindo o ensino médio como um vexame que compromete o futuro dos jovens brasileiros. Órgãos como o Conselho Estadual de Educação de São Paulo (CEE) são favoráveis à reforma em virtude dos resultados negativos identificados através do Exame Nacional do Ensino Médio (ENEM), colocando o país em uma situação retardatária, condenada ao atraso, e defendem a ampliação da jornada e o reforço do ensino profissionalizante.

Por outro lado, movimentos como a União Brasileira dos Estudantes Secundaristas (UBES) mostraram-se contrários à proposta da reforma, pois consideram que a "reforma" desvaloriza o pensamento crítico, não 
proporciona o diálogo, e seu processo de implantação mostra-se confuso, inferindo um despreparo da atual gestão. Assim, as opiniões contrarias às reformas chamam atenção para a limitação do pensamento, do senso crítico e da aquisição do conhecimento intelectual dos educandos. Eles ressaltam ainda que essas reformas foram colocadas de forma autoritária, sem ampla discussão com a parte interessada, como os profissionais da educação, a juventude e os estudantes, e principalmente a sociedade.

Logo, por essas séries de mudanças que irão acontecer com a educação brasileira, torna-se necessária ampla discussão e ponderações que serão relatadas em nossas considerações a seguir.

\section{Considerações finais}

Considerando que o Brasil é constituído de um sistema econômico capitalista na era do mundo globalizado, com uma sociedade consumista e produtiva que importa e exporta sua produção, interagindo internacionalmente com diversos países, principalmente com as maiores potências econômicas do planeta, necessita constantemente desenvolver suas capacidades de capital humano, econômico, tecnológico, social e cultural, a fim de atender as demandas e as novas exigências do mercado interno e mundial.

Sendo a educação um meio que transforma a sociedade, e que o sistema político social brasileiro está fundamentado no regime republicano e capitalista, temos em vista que ainda não existe uma intenção sólida da sociedade em mudar esta realidade nacional. $\bigcirc$ debate sobre a educação no Brasil é constante, principalmente na academia, e é marcado por diversas perspectivas sobre o tema. A pedagogia empreendedora surge, então, como um divisor de águas, e proporciona uma nova reflexão sobre a educação, conciliando as diferentes concepções sobre o tema em um novo modelo, que também precisa ser problematizado, em prol de uma mudança significativa dessa realidade. 
Assim, o empreendedorismo tornou-se um grande potencial de crescimento econômico, contribuindo para manter e/ou impulsionar a economia do país, gerando emprego e renda em um período difícil pelo qual o Brasil está passando; para pessoas que se encontram desencantadas pelo emprego, que buscam novas oportunidades de trabalho, novos desafios para transformarem suas vidas, deixando de ser empregadas para conquistarem seu próprio negócio, além de estabilidade e controle de suas rendas e sua vida pessoal.

Considerando a complexa reforma do ensino médio explícita na Lei supracitada, principalmente no que diz respeito à formação técnica e profissional dos educandos, vale discutir a proposta de implantação e/ou inclusão curricular da Pedagogia Empreendedora nas escolas públicas ou privadas, principalmente para atender a educação de jovens e adultos que também estão atuando no mercado do trabalho. Isso incentivará a formação de cidadãos proativos e empreendedores, vislumbrando a qualidade do ensino e do conhecimento, e também o desenvolvimento econômico, tecnológico, social e cultural do país.

Além disso, a pedagogia empreendedora pode ser uma forma de amenizar os efeitos dessa reforma, aprovada de forma acelerada em sem consulta popular, evitando que a formação do ensino médio brasileiro tenha como objetivo primário a aceleração do fornecimento de mão de obra para o mercado de trabalho. Isso porque a pedagogia empreendedora não tem em seus pilares essa visão reducionista da educação, que visa apenas à manutenção do emprego.

Enfim, deve-se levar em conta também que a pedagogia empreendedora não deve ser debatida apenas no contexto do ensino médio brasileiro. É uma proposta que deveria estar presente desde a educação infantil, no ensino fundamental, e até mesmo na Educação de Jovens e Adultos (EJA), que atende um público que abrange grande parte de jovens, adultos e até idosos, os quais já atuam no mercado de trabalho e estudam no contraturno. É necessário, por isso, rever os conteúdos 
trabalhados, de modo que estes se tornem mais interessantes a fim de minimizar os índices de evasão escolar.

Assim, precisa-se refletir sobre as mudanças no cenário socioeconômico e cultural da educação brasileira, desde a educação infantil até o ensino superior, sendo relevante discutir a Pedagogia Empreendedora como mais uma possibilidade na construção do conhecimento, o que potencializará novas oportunidades de formação educacional e profissional.

\section{REFERÊNCIAS}

BIESTA, G. Para além da aprendizagem: educação democrática para um futuro humano. Belo Horizonte: Autêntica, 2013.

BRASIL. Lei n 5.692/1971. Lei de Diretrizes e Bases da Educação Nacional.

BRASIL. Lei n 9.394/1996. Lei de Diretrizes e Bases da Educação Nacional.

BRASIL. Ministério da Educação. Secretaria de Educação Básica. Secretaria de Educação Continuada, Alfabetização, Diversidade e Inclusão. Secretaria de Educação Profissional e Tecnológica. Conselho Nacional da Educação. Câmara Nacional de Educação Básica. Diretrizes Curriculares Nacionais Gerais da Educação Básica. Ministério da Educação. Secretaria de Educação Básica. Diretoria de Currículos e Educação Integral. Brasília: MEC, SEB, DICEI, 2013.

DIÁRIO Oficial da União. República Federativa do Brasil. Imprensa Nacional. Atos do Poder Legislativo. Lei n 13.415/2017. Ano CLIV, n 35, seção 1, Brasília/DF, 17/02/2017.

DOLABELA, Fernando. Oficina do empreendedor. São Paulo: Cultura Editores Associados, 1999.

DOLABELA, Fernando. Pedagogia empreendedora. São Paulo: Cultura, 2003. Em: <http://portal.mec.gov.br/component/tags/tag/39691>. Acesso em: 08 mar. 2017. Em: <http:ubes.org.br/2016/5-motivos-por-que-a-ubes-e-contra-areforma-do-ensino-medio/>. Acesso em: 08 mar. 2017.

FILHO, Geraldo Francisco. Panorâmica das tendências e práticas

pedagógicas. 2. ed. rev. Campinas: Átomo, 2011. 
FREIRE, Paulo. Pedagogia da autonomia: saberes necessários à prática educativa. São Paulo: Paz e Terra, 1996.

FREIRE, Paulo. Pedagogia do oprimido. Rio de Janeiro: Paz e Terra, 1987/2014.

GAUTHIER, Clermont; TARDIF, Maurice. A pedagogia: teorias e práticas da antiguidade aos nossos dias. Petrópolis: Vozes, 2010.

GHEDIN, E. Epistemologia dos processos de ensino-aprendizagem e suas implicações à educação em ciências. In: GHEDIN, E. (org.). Teorias psicopedagógicas do ensino-aprendizagem. Boa Vista: UERR, 2012.

LIBÂNEO, José Carlos. Democratização da escola pública: pedagogia críticosocial dos conteúdos. 13. ed. São Paulo: Loyola, 1995.

LUCKESI, Cipriano Carlos. Avaliação da aprendizagem escolar: estudos e proposições. 19. ed. São Paulo: Cortez, 2003.

MARTINS, Carlos Benedito. O que é sociologia. 38. ed. São Paulo: Brasiliense, 1994.

MARX, Karl. Manuscritos econômicos filosóficos. São Paulo: Martin Claret, 2001.

SAVIANI, Demerval. Escola e Democracia. Edição Comemorativa. Campinas: Autores Associados, 1981/2008.

TEIXEIRA, Marcelo Manini. Educação científica e movimento C.T.S. no quadro das tendências pedagógicas no Brasil. Revista Brasileira de Pesquisa e Educação em Ciências. Disponível em:

<https://seer.lcc.ufmg.br/index.php/rbpec/article/view/2317>. Acesso em: 03 fev. 2017.

\section{SOBRE OS AUTORES:}

\section{Antônio José Müller}

Doutor em Educação, pela The University of Texas at El Paso; professor titular da Universidade Regional de Blumenau (FURB) no Programa de PósGraduação em Educação; membro do Grupo de pesquisa Educogitans. Email: antoniomuller2@hotmail.com

\section{Claudeney Licínio Oliveira}

Mestrando em Educação, pela Universidade Regional de Blumenau (FURB); membro do Grupo de pesquisa Educogitans. E-mail: deney.licinio@bol.com.br 


\section{Marcos Antonio Fari Junior}

Mestre em Educação, pela Universidade Regional de Blumenau (FURB); membro do Grupo de pesquisa Educogitans. E-mail: marcaovolei@yahoo.com.br

Recebido em: 22 de agosto de 2017. Aprovado em: 05 de outubro de 2017. 